\title{
Health disparities between island and mainland Puerto Ricans
}

\author{
Gloria Y. F. Ho, ${ }^{1}$ Hong Qian, ${ }^{1}$ Mimi Y. Kim, ${ }^{1}$ Thomas A. Melnik, ${ }^{2}$ \\ Katherine L. Tucker, ${ }^{3}$ Ivonne Z. Jimenez-Velazquez, ${ }^{4}$ \\ Robert C. Kaplan, ${ }^{1}$ Elizabeth T. Lee-Rey, ${ }^{5}$ Daniel T. Stein, ${ }^{6}$ \\ Winna Rivera, ${ }^{7}$ and Thomas E. Rohan ${ }^{1}$
}

Suggested citation Ho GYF, Quian H, Kim MY, Melnik TA, Tucker KL, Jimenez-Velazquez IZ, et al. Health disparities between island and mainland Puerto Ricans. Rev Panam Salud Publica. 2006;19(5):331-9.

ABSTRACT Objective. To detect health disparities among three populations-Puerto Ricans living in Puerto Rico as well as Puerto Ricans and non-Hispanic whites living on the United States (U.S.) mainland.

Methods. Data from two similarly designed surveys conducted in 1999-2000 were analyzed. The Behavioral Risk Factor Surveillance System (BRFSS) provided data on Puerto Ricans living on the island and on non-Hispanic whites in the U.S. Another survey of Puerto Ricans living in New York City provided data on mainland Puerto Ricans. The age-and sexstandardized weighted prevalences of various health parameters (e.g., obesity, diabetes, smoking, and physical illness) and indicators of access to health care (e.g., frequencies of routine checkups and diabetes care) were compared between populations by means of standardized rate ratios (SRR).

Results. Puerto Ricans living on the mainland and those living on the island had a similar prevalence of obesity ( $21 \%$ to $22 \%$ ). Compared with islanders, mainland Puerto Ricans had a higher prevalence of diabetes $(S R R=1.4 ; 95 \%$ confidence interval $[95 \% C I]=1.01$ to 2.0); those with diabetes also showed higher prevalences of smoking (SRR $=4.2 ; 95 \% C I=2.3$ to 7.7$)$ and physical illness (SRR $=1.5 ; 95 \% C I=1.1$ to 2.0) than Puerto Ricans living on the island. While mainland Puerto Ricans were similar to non-Hispanic whites in terms of their utilization of primary prevention and diabetes care, island Puerto Ricans trailed behind significantly. Conclusions. Puerto Ricans living on the U.S. mainland and those living in Puerto Rico both need to target lowering their prevalence of obesity and diabetes. For island Puerto Ricans, improved education about the significance of primary prevention and diabetes care is needed. For mainland Puerto Ricans, the accessibility of the primary health care system renders it a potentially effective venue for interventions, particularly for smoking cessation. More studies are warranted to identify factors associated with the poor health status observed in mainland Puerto Ricans.

Key words Health services accessibility, equity in access, ethnic groups, health status, Puerto Rico, United States of America.

1 Department of Epidemiology and Population Health, Albert Einstein College of Medicine, Bronx, New York, United States of America. All correspondence should be addressed to Gloria Y.F. Ho at: Department of Epidemiology and Population Health, Albert Einstein College of Medicine, 1300 Morris Park Avenue, Belfer Building \#1312, Bronx, NY 10461, USA; telephone: 7184303558 ; fax: 718430 3076; e-mail: ho@aecom.yu.edu
2 Bureau of Chronic Disease Epidemiology and Surveillance, New York State Department of Health Albany, New York, United States of America.

3 School of Nutrition Science and Policy, Tufts University, Boston, Massachusetts, United States of America.

4 Department of Internal Medicine, University of Puerto Rico, San Juan, Puerto Rico.
5 Department of Family and Social Medicine, Albert Einstein College of Medicine, Bronx, New York, United States of America.

6 Department of Medicine, Albert Einstein College of Medicine, Bronx, New York, United States of America.

7 School of Public Health, University of Puerto Rico, San Juan, Puerto Rico. 
The 3.4 million Puerto Ricans living on the United States (U.S.) mainland ("mainland Puerto Ricans") together with the 3.6 millions who live in Puerto Rico ("island Puerto Ricans") make up $18 \%$ of the U.S. Hispanic population and comprise the second largest Hispanic subgroup in the country (1). The majority of Puerto Ricans moved to the U.S. mainland in the 1950s and 1960s for economic opportunities and may have experienced acculturative stress, a language barrier, and socio-economic disadvantages $(2,3)$, and these factors could have affected their access to health care and their overall health status. Previous studies on health disparities in Puerto Ricans compared either mainland or island Puerto Ricans with non-Hispanic whites $(4,5)$, but data comparing mainland and island Puerto Ricans are limited. Such data could provide insights on how relocation from Puerto Rico to the U.S. mainland may affect the health status of Puerto Ricans and, particularly, on whether mainland and island Puerto Ricans have specific health problems that require different public health attention. In this study, we looked for health disparities between three populationsPuerto Ricans living in Puerto Rico, Puerto Ricans residing in New York City (NYC), where a major concentration of mainland Puerto Ricans lives, and U.S. non-Hispanic whites-and compared various indicators of health status and health care utilization in these populations.

\section{MATERIALS AND METHODS}

\section{Study data}

We analyzed data obtained in 19992000 from two randomly sampled surveys: the Behavioral Risk Factor Surveillance System (BRFSS) provided data on island Puerto Ricans and U.S. non-Hispanic whites, while the second survey, known as the New York City survey (NYC survey), provided data on Puerto Ricans residing in NYC. The BRFSS, an ongoing random-digitdialed telephone survey of adults aged $\geq 18$ years sponsored by the Centers for Disease Control and Prevention in Atlanta, Georgia, is conducted nationwide, including Puerto Rico (6). The survey monitors the prevalence of common health problems, major behavioral risk factors, and health care utilization. In this study, we analyzed the 1999 BRFSS data on Puerto Rico as well as on non-Hispanic whites in three neighboring states, namely New York, New Jersey, and Connecticut, where $50 \%$ of mainland Puerto Ricans reside (1). As Puerto Ricans living on the U.S. mainland acculturate to their new regional lifestyle and culture, they can be expected to have health status, risk factor, and health care utilization patterns that are more comparable to those of non-Hispanic whites living in these states than to the rest of non-Hispanic whites in the U.S. The numbers of BRFSS respondents were 3052 Puerto Rican residents of Puerto Rico and 6794 non-Hispanic whites in the states of New York, New Jersey, and Connecticut.

While it is possible to identify island Puerto Ricans by the state code in the BRFSS database, it is impossible to identify mainland Puerto Ricans among all Hispanic BRFSS respondents, since Hispanics are not further distinguished by their ethnic subgroups. As a result, it was not feasible to obtain an internal comparison group of mainland Puerto Ricans from the BRFSS. The NYC survey, conducted by the New York State Department of Health from June 1999 through June 2000 in Puerto Ricans living in NYC, provided a sample of mainland Puerto Ricans (7). The methodology of the NYC survey closely resembled that of the BRFSS protocol; it was a random-digit-dialed telephone survey, and the majority of its survey questions were the same as those in the BRFSS. It surveyed 1304 adults in NYC who were $\geq 18$ years old and identified themselves as Puerto Ricans. The participants were either born in Puerto Rico or they were of Puerto Rican descent and born elsewhere (mostly on the U.S. mainland). As the NYC survey was designed to examine the prevalence of diabetes and its risk factors among Puerto Ricans living in NYC, respondents with diabetes were oversampled: all respondents reporting diabetes were retained in the sample, and those without diabetes were selected at a rate to yield approximately equal numbers of respondents with and without diabetes. Such selection of participants by diabetes status was adjusted for by incorporating the weighting factors in the data analysis as described below.

\section{Statistical analyses}

To ensure the comparability of data from the two surveys, only those questions that were asked and coded exactly the same way in both surveys were analyzed. Variables describing the demographic characteristics of the three study populations included age, gender, education, current employment status, and annual household income. Self-reported indicators for health status and health risk factors included body mass index (BMI), which was calculated as weight in kilograms divided by height in meters squared $\left(\mathrm{kg} / \mathrm{m}^{2}\right)$, smoking status, diagnosis of diabetes, high blood pressure or high blood cholesterol as measured by a health professional, and the number of days in the past 30 days that the participant had any physical illness or injury. Utilization of and access to health care were measured by frequencies of routine checkups and preventive care (e.g., influenza or pneumococcal vaccination, having had blood pressure and cholesterol checked by a doctor within the past year, and whether the participant had health insurance coverage.

Comparisons of these health parameters among the three study populations were stratified by diabetes status to avoid confounding, since having diabetes influences health status and the frequency of health care utilization, and the study populations had different prevalences of diabetes. Among individuals with diabetes, health care utilization was also measured by 
TABLE 1. Weighted demographic distributions (in percentages) among Puerto Ricans living in New York City (NYC) and on the island of Puerto Rico and U.S. non-Hispanic whites living in New Jersey, New York, and Connecticut

\begin{tabular}{|c|c|c|c|}
\hline & $\begin{array}{c}\text { Island } \\
\text { Puerto Ricans }\end{array}$ & $\begin{array}{c}\text { NYC } \\
\text { Puerto Ricans }\end{array}$ & $\begin{array}{c}\text { Tri-state } \\
\text { non-Hispanic whites }\end{array}$ \\
\hline $\begin{array}{l}\text { Weighted population size } \\
\text { Age (in years) }\end{array}$ & 2753873 & 571363 & 15579218 \\
\hline $\begin{array}{l}18-44 \\
45-64 \\
\geq 65\end{array}$ & $\begin{array}{l}58.0^{a, b} \\
27.4^{b} \\
14.6^{a, b}\end{array}$ & $\begin{array}{r}63.9^{c} \\
27.3^{c} \\
8.8^{c}\end{array}$ & $\begin{array}{l}47.2 \\
30.5 \\
22.3\end{array}$ \\
\hline $\begin{array}{l}\text { Male } \\
\text { Education }\end{array}$ & $47.1^{a}$ & $44.3^{c}$ & 47.5 \\
\hline $\begin{array}{l}<\text { High school } \\
\text { High school graduate } \\
>\text { High school }\end{array}$ & $\begin{array}{l}27.1^{a, b} \\
26.5^{b} \\
46.4^{a, b}\end{array}$ & $\begin{array}{l}44.3^{c} \\
21.9^{c} \\
33.8^{c}\end{array}$ & $\begin{array}{r}6.8 \\
32.2 \\
61.0\end{array}$ \\
\hline $\begin{array}{l}\text { Employed } \\
\text { Annual household income }\end{array}$ & $45.2^{a, b}$ & $53.5^{\mathrm{c}}$ & 64.5 \\
\hline $\begin{array}{l}<\text { US } \$ 10000 \\
\$ 10000-\$ 19999 \\
\$ 20000-\$ 34999 \\
\geq \$ 35000\end{array}$ & $\begin{array}{l}40.0^{a, b} \\
31.7^{a, b} \\
19.8^{b} \\
8.5^{a, b}\end{array}$ & $\begin{array}{l}15.2^{c} \\
21.7^{c} \\
29.3^{c} \\
33.8^{c}\end{array}$ & $\begin{array}{r}2.8 \\
9.8 \\
22.9 \\
64.5\end{array}$ \\
\hline
\end{tabular}

whether or not they followed the guidelines of the American Diabetes Association (ADA) for diabetes care, such as having seen a doctor for diabetes at least twice a year and having had their eyes and feet checked within the past year (8).

Using the weighting factors provided in the BRFSS and NYC survey databases, representative populationbased prevalence data were derived to reflect the age and sex distribution of each of the three populations during 1999, while adjusting for the probability of selection, non-response rate, and telephone non-coverage. Weighted prevalence data of the three populations were then standardized by age and sex to the U.S. Census 2000 population (9). SUDAAN software (release 9.0) was used for standardization and variance estimation of the prevalence (10). The standardized weighted prevalence of each health parameter was compared between two populations (e.g., islanders versus NYC Puerto Ricans) by calculating a standardized rate ratio (SRR) and its 95\% confidence interval as follows $(11,12)$ :

$$
\left(P_{1} / P_{2}\right)^{1 \pm 1.96 / \Phi}
$$

where

$$
\Phi=\left(P_{1}-P_{2}\right) / \sqrt{S E_{1}^{2}+S E_{2}^{2}}
$$

$P_{1}$ and $P_{2}$ are standardized rates from two populations, $P_{1} / P_{2}$ is the SRR, and $S E_{1}$ and $S E_{2}$ are the standard errors for $P_{1}$ and $P_{2}$, respectively. Two populations are significantly different in their standardized rates at the 0.05 level if the 95\% confidence interval of the SRR excludes one. For simplicity, the standardized weighted prevalences (as percentages) of health parameters for the three populations are presented in Tables 1-4 in this paper, but pairwise statistical comparisons between any two populations were based on the SRR method.

\section{RESULTS}

The demographic characteristics of island Puerto Ricans, NYC Puerto Ricans, and non-Hispanic whites in New York, New Jersey, and Connecticut are shown in Table 1. Of the three populations, NYC Puerto Ricans were the youngest and the least educated, on average. Although NYC Puerto Ricans were financially better off than island Puerto Ricans as reflected by average employment status and annual household income, they trailed behind U.S. non-Hispanic whites. Among NYC Puerto Ricans, $46 \%$ of them were born in Puerto Rico, $53 \%$ on the U.S. mainland, and $1 \%$ in foreign countries. The latter two groups were combined in further analyses.

\section{Prevalence of obesity and diabetes}

Table 2 shows the standardized weighted prevalence of obesity (BMI $\geq 30 \mathrm{~kg} / \mathrm{m}^{2}$ ) in the three populations. The data were not further stratified by age, since the prevalence of obesity was not associated with age, and the differences in prevalence among the three populations were consistent across various age groups (data not shown). The prevalence of obesity was similar between Puerto Ricans living 
TABLE 2. Weighted prevalence of obesity (BMI $\geq 30 \mathrm{~kg} / \mathrm{m}^{2}$ ) and diabetes in Puerto Ricans living in Puerto Rico and in New York City (NYC) and U.S. non-Hispanic whites living in New Jersey, New York, and Connecticut

\begin{tabular}{|c|c|c|c|c|c|c|}
\hline & \multicolumn{2}{|c|}{$\begin{array}{c}\text { Island } \\
\text { Puerto Ricans }\end{array}$} & \multicolumn{2}{|c|}{$\begin{array}{c}\text { NYC } \\
\text { Puerto Ricans }\end{array}$} & \multicolumn{2}{|c|}{$\begin{array}{c}\text { Tri-state } \\
\text { non-Hispanic whites }\end{array}$} \\
\hline & $\%$ & (SE) & $\%$ & (SE) & $\%$ & (SE) \\
\hline \multicolumn{7}{|l|}{ Obesity } \\
\hline Male $^{\mathrm{a}}$ & 22.2 & $(1.4)^{\mathrm{b}}$ & 18.6 & (3.3) & 17.4 & (1.0) \\
\hline Female $^{\mathrm{a}}$ & 21.5 & $(1.1)^{\mathrm{b}}$ & 23.0 & $(3.2)^{c}$ & 13.7 & $(0.8)$ \\
\hline Total $^{\mathrm{d}}$ & 21.9 & $(0.9)^{b}$ & 21.0 & $(2.3)^{c}$ & 15.5 & $(0.6)$ \\
\hline $18-44$ & 1.5 & $(0.5)^{\mathrm{e}}$ & 5.0 & $(1.7)^{c}$ & 1.0 & $(0.3)$ \\
\hline $45-64$ & 16.7 & $\left(2.3^{b}\right.$ & 15.7 & $(4.8)$ & 6.9 & (1.1) \\
\hline$\geq 65$ & 20.8 & $(2.7)^{\mathrm{b}}$ & 42.1 & (15.7) & 11.5 & (1.9) \\
\hline \multicolumn{7}{|c|}{ Females (by age in years) } \\
\hline $18-44$ & 2.8 & $(0.7)$ & 5.1 & $(1.1)^{\mathrm{c}}$ & 1.4 & $(0.4)$ \\
\hline $45-64$ & 16.4 & $(1.6)^{b}$ & 18.0 & $(2.6)^{c}$ & 4.8 & (0.8) \\
\hline$\geq 65$ & 30.0 & $(2.6)^{b}$ & 42.3 & $(9.9)^{c}$ & 10.4 & (1.5) \\
\hline Total $^{\mathrm{d}}$ & 10.5 & $(0.6)^{\mathrm{b}, \mathrm{e}}$ & 14.9 & $(2.1)^{\mathrm{c}}$ & 4.1 & (0.3) \\
\hline
\end{tabular}

on the island and in NYC. Further analysis by birthplace of NYC Puerto Ricans also did not reveal any substantial differences in obesity among subgroups of Puerto Ricans (data not shown). Puerto Rican women living on the island and in NYC were both significantly more likely to be obese than U.S. non-Hispanic white women (SRRs $=1.6$ and $1.7 ; 95 \%$ CIs $=1.4$ to 1.8 and 1.2 to 2.4 , respectively). The differences between Puerto Rican men and U.S. non-Hispanic white men were small $($ SRRs $=1.3$ and $1.1 ; 95 \%$ CIs = $1.1-1.5$ and $0.7-1.6$, for island and NYC Puerto Ricans, respectively).

Table 2 shows that the prevalence of diabetes was two- to fourfold higher in both island and NYC Puerto Ricans than in U.S. non-Hispanic whites, and this trend was observed in both men and women. NYC Puerto Ricans had a significantly higher age- and sexadjusted prevalence of diabetes than island Puerto Ricans (SRR $=1.4 ; 95 \%$ $\mathrm{CI}=1.01$ to 2.0 ). The largest difference between the two Puerto Rican populations was seen in the 18- to 44-year age group (SRR $=2.3 ; 95 \% \mathrm{CI}=1.2$ to 4.5$)$, suggesting that Puerto Ricans in NYC might be diagnosed with diabetes earlier than island Puerto Ricans. In a subgroup analysis among those who were diabetic and $\geq 65$ years old, diagnosis before the age of 45 was seen in 27.5\% of NYC Puerto Ricans and in $14.7 \%$ of island Puerto Ricans. However, this difference was not statistically significant due to the small number of Puerto Ricans $\geq 65$ years old in the NYC Survey.

\section{Health status and diabetes care among individuals with diabetes}

The health status and access to diabetes care of individuals with diabetes are shown in Table 3. Despite the fact that all three groups had a similar prevalence of hypertension and hypercholesterolemia, NYC Puerto Ricans had the worst health indicators. The disparities between NYC Puerto Ricans and island Puerto Ricans were greater than those between NYC Puerto Ricans and U.S. non-Hispanic whites. For example, NYC Puerto Ricans were significantly more likely to be overweight (BMI $\geq 25 \mathrm{~kg} / \mathrm{m}^{2}$ ) than island Puerto Ricans $(\mathrm{SRR}=1.5 ; 95 \%$ $\mathrm{CI}=1.2$ to 1.7$)$ and U.S. non-Hispanic whites $(\mathrm{SRR}=1.3 ; 95 \% \mathrm{CI}=1.1$ to 1.5$)$; they had the highest prevalence of physical illness in the past 30 days as compared to islanders (SRR $=1.5 ; 95 \%$ CIs $=1.1$ to 2.0$)$ and U.S. non-Hispanic whites $(\mathrm{SRR}=1.3 ; 95 \% \mathrm{CI}=1.01$ to $1.7)$; and the prevalence of smoking in NYC Puerto Ricans was four times higher than in island Puerto Ricans $(\mathrm{SRR}=4.2 ; 95 \% \mathrm{CI}=2.3$ to 7.7$)$ and 
TABLE 3. Age and sex standardized weighted prevalence of health status and diabetes care among individuals who had diabetes-Puerto Ricans living in Puerto Rico and in New York City (NYC) and U.S. non-Hispanic whites living in New Jersey, New York, and Connecticut

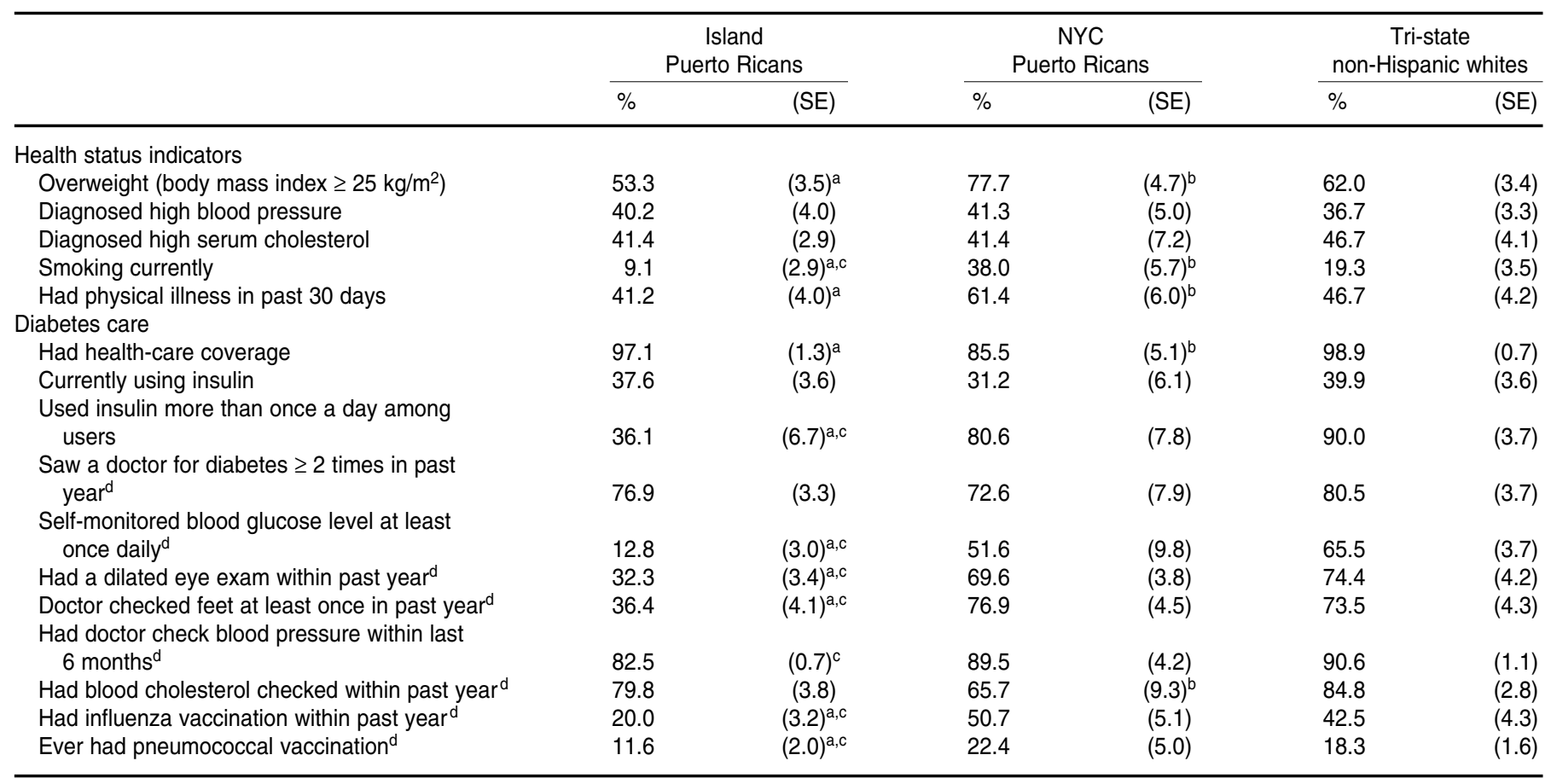

a $P<0.05$ comparing island Puerto Ricans and NYC Puerto Ricans.

b $P<0.05$ comparing NYC Puerto Ricans and tri-state non-Hispanic whites.

c $P<0.05$ comparing island Puerto Ricans and tri-state non-Hispanic whites.

d Frequency of diabetes care according to the recommendations of the American Diabetes Association.

TABLE 4. Age and sex standardized weighted prevalence of health status and access to primary health care among individuals without diabetes-Puerto Ricans living in Puerto Rico and in New York City (NYC) and U.S. non-Hispanic whites living in New Jersey, New York, and Connecticut

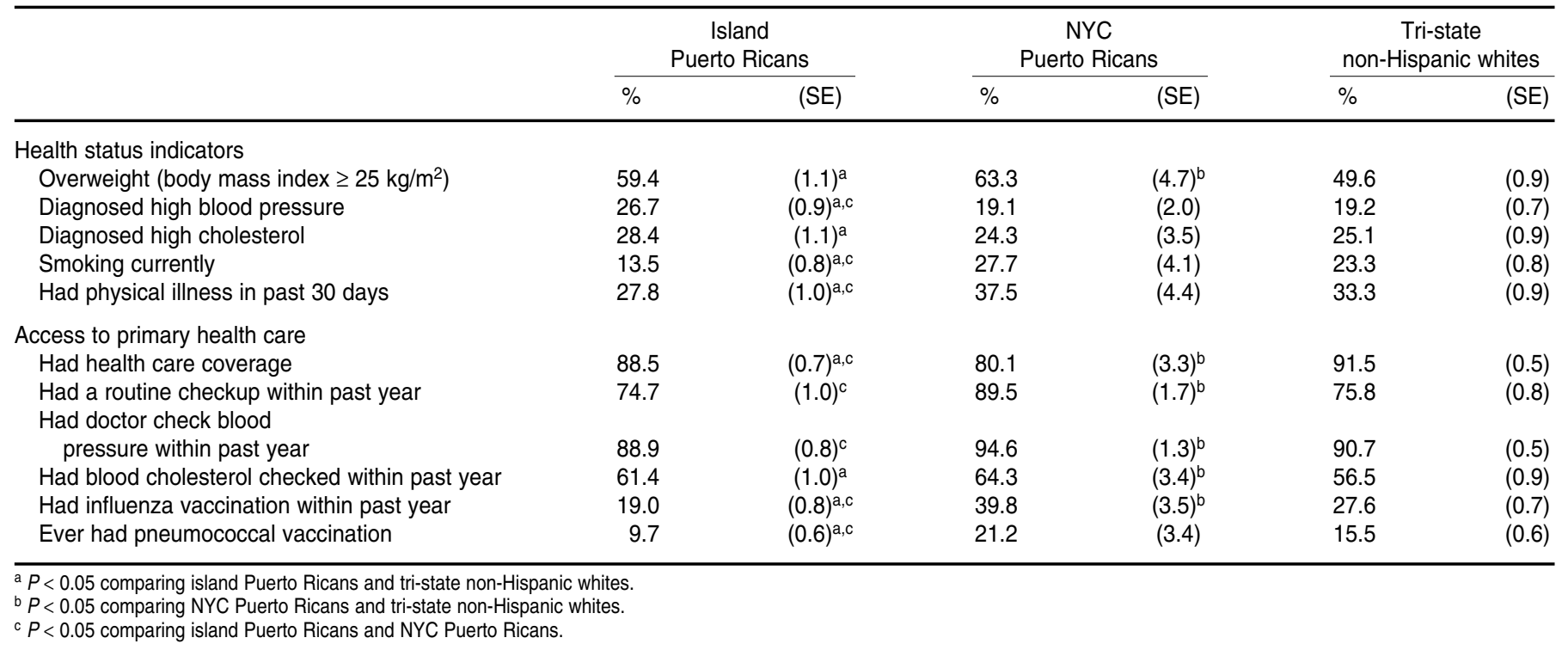


twice as high as in U.S. non-Hispanic whites (SRR $=2.0 ; 95 \% \mathrm{CI}=1.2$ to 3.2 ). Island Puerto Ricans had the lowest reported prevalence of smoking (9\%). These differences did not appear to be due to smoking cessation after diabetes diagnosis, since the proportions of former smokers were similar in the three populations (data not shown).

As NYC Puerto Ricans had the lowest health insurance coverage among the three study populations, this might have had an adverse impact on their diabetes care. Surprisingly, the proportions of NYC Puerto Ricans who followed the guidelines of the ADA for diabetes care generally matched those of non-Hispanic whites, whereas island Puerto Ricans trailed significantly behind. For example, the proportion of NYC Puerto Ricans who had had a dilated eye examination within the past year was similar to that of U.S. non-Hispanic whites, whereas island Puerto Ricans were two times less likely to have had this procedure than NYC Puerto Ricans (SRR = 0.5; $95 \% \mathrm{CI}=0.4-0.6)$. Island Puerto Ricans actually had more frequent diabetes care visits than the ADA standard of 2-4 times per year $(54.6 \%$ had $\geq 5$ visits in the past year vs. $41.7 \%$ of NYC Puerto Ricans and $38 \%$ of U.S. non-Hispanic whites), but they did not appear to receive the recommended diabetes care. We also analyzed the NYC Puerto Ricans by place of birth (Puerto Rico vs. U.S. mainland/other countries) and found the two groups to be similar in health status and diabetes care (data not shown).

\section{Health status and access to primary care in individuals without diabetes}

Similar to individuals with diabetes, non-diabetic NYC Puerto Ricans were comparable to non-Hispanic whites but different from island Puerto Ricans in terms of their health status (Table 4). The prevalence of hypertension among island Puerto Ricans was significantly higher than the prevalence of hypertension among NYC Puerto Ricans (SRR $=1.4 ; 95 \% \mathrm{CI}=1.2$ to 1.7$)$, which was equivalent to that in non-Hispanic whites. Also, the proportions of smokers among both NYC Puerto Ricans and U.S. non-Hispanic whites were about twofold higher than among island Puerto Ricans. The three populations showed statistically significant differences in many indicators of health care access due to the large sample size of non-diabetics, but most of these differences were small (e.g., SRRs approximately 1.1 to 1.2). The largest disparity was seen in the utilization of primary preventive care; NYC Puerto Ricans were two times more likely than island Puerto Ricans to have been vaccinated against influenza or pneumococcal disease $($ SRRs $=2.1$ and $2.2 ; 95 \%$ CIs $=1.6$ to 2.7 and 1.4 to 3.5 , respectively). NYC Puerto Ricans who were born in Puerto Rico had lower health care coverage $(69.2 \%)$ than those who were born elsewhere (84.5\%). Nevertheless, access to health care appeared to be similar in both (data not shown). For example, the proportions of responders who had had an influenza vaccination within the past year were $38.5 \%$ for those who were born in Puerto Rico and $35.3 \%$ for Puerto Ricans who were born outside of Puerto Rico $(\mathrm{SRR}=1.1 ; 95 \% \mathrm{CI}=0.8$ to 1.5$)$.

\section{DISCUSSION}

Puerto Ricans have been included in several national health surveys such as the BRFSS, the National Health Interview Survey (NHIS), and the Hispanic Health and Nutrition Examination Survey (HHANES), but none of these surveys provides comparative data between Puerto Ricans living in Puerto Rico and on the U.S. mainland. The study reported here is unique in that it combined data from two similarly designed population-based surveys to examine health disparities between island Puerto Ricans and mainland Puerto Ricans.

Several observations suggest that NYC Puerto Ricans are reasonably representative of U.S. mainland Puerto Ricans. About a quarter of all 3.4 million Puerto Ricans living on the U.S. mainland cluster in New York City, the municipality with the highest concentration of Puerto Ricans in the U.S. (1). We compared the weighted distributions of Puerto Ricans in New York City that participated in the NYC Survey with those of mainland Puerto Ricans $\geq 18$ years of age from the 2000 U.S. Census with respect to a number of demographic factors and found them to be comparable in terms of age (8.8\% and $8.3 \% \geq 65$ years old, respectively), gender ( $44.3 \%$ and $48.0 \%$ male, respectively), annual household income $(36.9 \%$ and $34.8 \%<\$ 20000$, respectively), and educational level (41.8\% and $36.7 \%$ non-high school graduates among persons $\geq 25$ years old, respectively) (13-15). In addition, our findings that NYC Puerto Ricans had higher prevalences of smoking and physical illness than U.S. non-Hispanic whites are consistent with NHIS reports for mainland Puerto Ricans (4).

In various immigrant populations in the U.S., first-generation immigrants who are foreign-born are often less likely to be obese than those who are U.S.-born, and BMI is positively correlated with the number of years of residence in the U.S. (16). Therefore, one would expect obesity to be a more serious health problem in mainland Puerto Ricans, particularly those who are U.S.born, than in those who live in Puerto Rico. Interestingly, our data did not support this notion and showed that both Puerto Rican populations had a similarly high prevalence of obesity. One possible explanation is that the traditional lifestyle in the native Puerto Rican population is not healthful, and acculturation in Puerto Ricans living on the U.S. mainland may confer some advantages in thwarting a rise in the obesity rate, if not decreasing it. We analyzed the lifestyle variables available in the 2000 BRFSS and found that only $7 \%$ of the population in Puerto Rico met the guideline of consuming $\geq 5$ servings of fruits and vegetables per day. Some studies suggest that although mainland Puerto Ricans in general have adopted a typical American diet that is high in fat, those who are ac- 
culturated also consume a diversity of foods, such as cereals and fruits, that are not common on the island; this nontraditional diet is associated with a decreased prevalence of total and central obesity (17-19). The 2000 BRFSS data also indicate that the population in Puerto Rico is sedentary, with 55\% reporting no physical activity in the past month as compared to $24 \%$ of nonHispanic whites in the three states included in our study. Mainland Puerto Ricans appear to track the lifestyle of U.S. non-Hispanic whites, as suggested by various health indicators in our study; thus, it is possible that some acculturated U.S. mainland Puerto Ricans are more physically active than Puerto Ricans living on the island.

Another advantage for Puerto Ricans residing on the U.S. mainland is an improvement in health care, as indicated by higher frequencies of routine checkups and preventive care in that group as compared to island dwellers. Also, higher proportions of Puerto Ricans who reside on the U.S. mainland follow the recommended ADA guidelines for diabetes care, as compared to island Puerto Ricans. It is possible that the increased prevalence and earlier diagnosis of diabetes in mainland Puerto Ricans relative to island Puerto Ricans may be partly attributed to greater utilization of primary health care services and hence to higher diabetes detection on the mainland.

Puerto Ricans living on the U.S. mainland also had a higher prevalence of smoking and poorer health status than did island dwellers. There was a two- to fourfold difference in smoking prevalence between mainland and island Puerto Ricans. The prevalence of physical illness was 1.3 to 1.5 times higher in mainland Puerto Ricans than in islanders. Our results are consistent with those reported by the NHIS to the effect that mainland Puerto Ricans, compared to other Hispanic subgroups and U.S. non-Hispanic whites, had the worst health indicators in terms of limited activity, number of bed-ridden disability days, and hospitalizations (4).

The Puerto Rico Health Reform initiated in 1993 guarantees access to health care for the indigent population of Puerto Rico. Unlike mainland Puerto Ricans, those living on the island do not face obstacles to health care due to lack of insurance coverage and language barriers. Yet, primary preventive care and diabetes care among islanders were poorer than among the other two study populations. One study in Puerto Rico showed that services related to diabetes control, such as blood glucose and glycosylated hemoglobin testing, were less frequently provided to individuals insured by the Puerto Rican Health Reform than to those who had private insurance, and the complications of diabetes were two times more common in the former group (21). On the other hand, island Puerto Ricans had the lowest prevalence of smoking among the three study populations, and this may partially explain the difference in health status between mainland and island Puerto Ricans.

There are a few weaknesses in this study. Firstly, the NYC survey was not designed to examine health disparities, so there are limited data on the prevalence of common chronic and infectious diseases as well as on health-related behavior, as compared to the BRFSS. Secondly, although our results surrounding access to primary health care and diabetes care in mainland Puerto Ricans are encouraging, they should be interpreted with caution. Our study did not provide information on the access to and quality of secondary health care and on whether or not diabetes is adequately controlled in the study populations. A study in Massachusetts showed that elderly Puerto Ricans who had diabetes were significantly less likely to have it under control than U.S. non-Hispanic whites (20).

In summary, obesity and diabetes are significant health problems among Puerto Ricans who live on the U.S. mainland and those who reside on the island of Puerto Rico. Diabetes is the third leading cause of death in both groups, and mortality from diabetes has been increasing markedly in Puerto Rico, particularly in individuals $\geq 65$ years of age (22). The low utilization of primary health care services and inadequate diabetes care in Puerto Rico call for improvements in education for the public as well as for primary health care providers about the prevention and control of obesity and diabetes. The high smoking rate and poor health status, especially among persons with diabetes, are additional health concerns for mainland Puerto Ricans. Despite the expected financial and language barriers to health care faced by Puerto Ricans living on the U.S. mainland, this group clearly manages to access the primary care system, which could be an effective venue to implement interventions for weight control, prevention and control of diabetes, and smoking cessation. More studies are warranted to examine if the acculturated lifestyle, quality of health services, access to secondary health care, and effectiveness in controlling diabetes and its complications are factors associated with the poor health status of mainland Puerto Ricans. 


\section{REFERENCES}

1. United States Census Bureau. Table QT-P9 Hispanic or Latino by Type: 2000. Census 2000 summary file 1 (SF1). Accessed on April 20, 2006. Available at http://factfindercensus gov/, 2000.

2. Ramírez de Arellano AB. Cancer in Puerto Rican women. In: Glanz K, ed. Cancer in women of color. Accessed on April 20, 2006. Available at http://72.14.207.104/search?q= cache:kwF7fRzasL4J:cancercontrol.cancer.gov/ womenofcolor/pdfs/puerto_rican-chapter. pdf.

3. Cortés DE, Rogler LH. Health status and acculturation among Puerto Ricans in New York City. J Gen Cult Health. 1996;1:267-76.

4. Hajat A, Lucas JB, Kington R. Health outcomes among Hispanic subgroups: data from the National Health Interview Survey, 199295. Advance Data from vital and health statistics; no. 310. Hyattsville (MD): National Center for Health Statistics; 2000.

5. Ahluwalia IB, Mack KA, Murphy W, Mokdad AH, Bales VS. State-specific prevalence of selected chronic disease-related characteristicsBehavioral Risk Factor Surveillance System, 2001. MMWR Surveill Summ. 2003;52:1-80.

6. Centers for Disease Control and Prevention. Behavioral Risk Factor Surveillance System. Atlanta (GA): CDC; 1999.

7. Melnik TA, Hosler AS, Sekhobo JP, Duffy TP, Tierney EF, Engelgau MM, et al. Diabetes prevalence among Puerto Rican adults in New York City, NY, 2000. Am J Public Health. 2004;94:434-7.

8. American Diabetes Association. Standards of medical care in diabetes. Diabetes Care. 2005; 28:S4-36.
9. United States Census Bureau. Table QT-P1 Age groups and sex: 2000. Census 2000 summary file 1 (SF1). Accessed on April 20, 2006. Available at http://factfindercensusgov/, 2000.

10. Research Triangle Institute. SUDAAN Language Manual, Relsease 9.0. Research Triangle Park (NC): Research Triangle Institute; 2004.

11. Miettinen OS. Standardization of risk ratios. Am J Epidemiol. 1972;96:383-8.

12. International Agency for Research on Cancer. Comparison between registries: agestandardized rates. In: Parkin DM, Muir CS, Whelan SL, Gao YT, Ferlay J, Powell J, eds. Cancer incidence in five continents. Lyon: International Agency for Research on Cancer; 1992:865-70.

13. United States Census Bureau. Table PCT88. Household income in 1999. Census 2000 summary file 4 (SF 4). Accessed on April 20, 2006. Available at http://factfindercensusgov/; 2000.

14. United States Census Bureau. Table PCT43. Sex by place of birth by citizenship status. Census 2000 summary file 4 (SF 4). Accessed on April 20, 2006. Available at http://fact findercensus gov/, 2000.

15. United States Census Bureau. Table PCT65. Sex by age by educational attainment for the population 18 years and over. Census 2000 summary file 4 (SF 4). Accessed on April 20, 2006. Available at http://factfindercensus gov/, 2000.

16. Goel MS, McCarthy EP, Phillips RS, Wee CC. Obesity among US immigrant subgroups by duration of residence. JAMA. 2004;292: 2860-7.
17. Lin H, Bermudez OI, Tucker KL. Dietary patterns of Hispanic elders are associated with acculturation and obesity. J Nutr. 2003;133: 3651-7.

18. Bermudez OI, Falcon LM, Tucker KL. Intake and food sources of macronutrients among older Hispanic adults: association with ethnicity, acculturation, and length of residence in the United States. J Am Diet Assoc. 2000; 100:665-73.

19. Sanjur D, Immink MDC, Colon M, Bentz L, Burgos M, Alicea-Santana S. Trends and differentials in dietary patterns and nutrient intake among migrant Puerto Rican families. Arch Latinoam Nutr. 1986;36:625-41.

20. Tucker KL, Bermudez OI, Castaneda C. Type 2 diabetes is prevalent and poorly controlled among Hispanic elders of Caribbean origin. Am J Public Health. 2000;90:1288-93.

21. Perez-Perdomo R, Perez-Cardona CM, DisdierFlores OM. Health disparities between diabetic patients under private and public health coverage in Puerto Rico, 2000. PR Health Sci J. 2003:22:363-8.

22. Perez-Perdomo R, Perez-Cardona C, SuarezPerez EL. Trends in diabetes mellitus mortality in Puerto Rico: 1980-1997. PR Health Sci J. 2001;20:19-24.

Manuscript received 21 December 2005. Revised version accepted for publication 14 April 2006.

RESUMEN Objetivo. Detectar disparidades de salud entre tres poblaciones: puertorriqueños que viven en Puerto Rico, así como puertorriqueños y personas no hispanas de raza blanca que viven en tierra firme estadounidense.

\section{Disparidades de salud entre puertorriqueños que viven en la isla de Puerto Rico y en tierra firme estadounidense}

Métodos. Se analizaron los datos obtenidos mediante dos encuestas de similar diseño que se realizaron en 1999-2000. El Sistema de Vigilancia de Factores de Riesgo Conductuales proporcionó datos acerca de los puertorriqueños radicados en la isla y de residentes de Estados Unidos de raza blanca que no son hispanos. Otra encuesta de puertorriqueños radicados en la Ciudad de Nueva York aportó datos acerca de los puertorriqueños que residían en tierra firme estadounidense. Se usaron las razones de las tasas estandarizadas (standardized rate ratios, SRR) para hacer las comparaciones interpoblacionales de las prevalencias ponderadas, estandarizadas por edad y sexo, de varios parámetros (obesidad, diabetes, tabaquismo y dolencias físicas) y de indicadores de acceso a la atención sanitaria (frecuencia de los exámenes de rutina y de la atención de la diabetes).

Resultados. Los puertorriqueños que vivían en tierra firme estadounidense y los que vivían en la isla tuvieron una prevalencia de obesidad parecida (21\% a $22 \%$ ). Comparados con los habitantes de la isla, los puertorriqueños radicados en tierra firme tuvieron una prevalencia de diabetes más alta $(S R R=1,4$; intervalo de confianza de 95\% [IC95\%]: 1,01 a 2,0); los que tenían diabetes también mostraron una mayor 
prevalencia de tabaquismo (SRR = 4,2; IC 95\%: 2,3 a 7,7) y de dolencias físicas (SRR = 1,5\%; IC95\%: 1,1 a 2,0) que los puertorriqueños que vivían en la isla. Mientras que los puertorriqueños en tierra firme se asemejaron a los blancos que no eran hispanos en cuanto a la utilización de servicios de prevención primaria y de atención de la diabetes, los puertorriqueños en la isla tenían cifras de utilización mucho más bajas.

Conclusiones. Tanto los puertorriqueños radicados en tierra firme estadounidense como los que viven en Puerto Rico tienen que ponerse como meta reducir su prevalencia de obesidad y diabetes. En el caso de los puertorriqueños en la isla, hace falta una mejor educación en torno a la importancia de la prevención primaria y de la atención de la diabetes. En el caso de los puertorriqueños en tierra firme, la accesibilidad del sistema de atención primaria hace que este sea idóneo para llevar a cabo diversas intervenciones, particularmente contra el hábito de fumar. Se necesitan más estudios para determinar qué factores se asocian con el mal estado de salud observado en puertorriqueños radicados en tierra firme.

Palabras clave Accesibilidad a los servicios de salud, equidad en el acceso, grupos étnicos, estado de salud, Puerto Rico, Estados Unidos de América. 